\title{
Oxidation by oxygen of liquid Al-Mg alloys during elaboration process
}

\author{
K. Surla (A B) , F. VAldivieso (A), M. Pij Olat ${ }^{\left(A^{*}\right)}$, M. Soustelle (A), M. Prin (B) \\ (A) Laboratoire des Procédés en Milieux Granulaires CNRS UMR 5148, Centre SPIN, Ecole \\ Nationale Supérieure des Mines, 158 Cours Fauriel, 42023 Saint-Etienne Cedex 2, \\ France \\ (B) Pechiney Centre de Recherches de Voreppe, Centr'Alp, BP 24, 38340 Voreppe
}

(*) mpijolat@emse.fr

Key words:

Al-Mg ; oxidation ; oxygen pressure ; kinetics ; growth reactivity

\begin{abstract}
The oxidation into MgO of an industrial Al-Mg alloy in the liquid state has been studied at $700^{\circ} \mathrm{C}$ by thermogravimetry. Since the kinetic curves were not reproducible, it was not possible to use them directly. Thus, it has been necessary to use a method based on the isolation method to obtain the influence of oxygen partial pressure on the areic reactivity (mole of $\mathrm{MgO} \cdot \mathrm{m}^{-2} \cdot \mathrm{s}^{-1}$ ) of growth of $\mathrm{MgO}$.
\end{abstract}

\section{Introduction}

During the elaboration of aluminium-magnesium alloys, the surface of the liquid metal may be oxidised, mainly leading to the formation of $\mathrm{MgO}$. The industrial system is quite complex, since several gases of the atmosphere can react with the alloys (oxygen, water vapour, nitrogen, carbon dioxide...).

So, we have studied a « simplified » system : the oxidation of an Al-Mg 5\% alloy by oxygen. The aim of this work is to obtain the influence of the oxygen pressure on the areic reactivity $\left(\right.$ mole of $\mathrm{MgO}^{-2} \mathrm{~m}^{-\mathrm{s}} \mathrm{s}^{-1}$ of growth of $\mathrm{MgO}$, and to propose a reaction mechanism able to account for the experimental results, in order to predict the behaviour of the alloy in industrial conditions of elaboration and to limit its oxidation.

After giving the oxidation kinetic curves, the methodology used for the kinetic study of the $\mathrm{MgO}$ growth will be detailed. Finally, the influence of the oxygen pressure on the areic reactivity of growth of $\mathrm{MgO}$ will be obtained, and thanks to the results of an IR study, some indications for a reaction mechanism will be given.

\section{Experimental}

The alloy is an industrial Al-Mg 5\% alloy, supplied by Pechiney. The samples are cylinders of $1 \mathrm{~mm}$ height and 9mm diameter (this height was chosen in order to ensure an constant oxygen pressure around the sample). For higher samples (15mm to $3.5 \mathrm{~mm}$ ), more oxidised parts were observed (a ring of white powder at the surface of the samples), the localisation of this ring along the cylinders varying with the oxygen pressure fixed for the experiment. Thus, we have assumed that a gradient of oxygen pressure exist along the high samples. This was not observed for the 1mm-high cylinders.

The oxidation of the liquid alloy was followed by isothermal thermogravimetry at $700^{\circ} \mathrm{C}$ (thermobalance SETARAM TAG 24). The experiments were carried out at atmospheric pressure, under a flowing mixture of helium and oxygen $\left(11 . h^{-1}\right)$, the partial pressures being controlled by mass-flowmeters (Brooks 5850E).

The heating and the melting of the samples were carried out under oxygen at atmospheric pressure since it has been observed that a high oxygen pressure allows to limit the oxidation of the liquid alloy; the oxygen pressure chosen for the experiment is established after 30 minutes of isotherm at $700^{\circ} \mathrm{C}$. The experiments of simultaneous calorimetry and 
thermogravimetry were performed using a SETARAM TG-DSC 111. In situ IR study was carried out with a Spectra Tech cell (model 0030-13) and a spectrometer Biorad FTS 185. Micrographs were obtained on a scanning electron microscope J eol J SM 840.

\section{Experimental results}

As shown in a previous study [1], MgO is the first phase which appears during the reaction, up to $2 \%$ weight increase. Above $2 \%$ (that is a residual magnesium activity in the alloy lower than 0.023), $\mathrm{MgAl}_{2} \mathrm{O}_{4}$ is the thermodynamically stable phase as represented in figure 1 , its formation being confirmed by X-Ray diffraction. The kinetic curves will then be limited to a weight increase of $2 \%$.

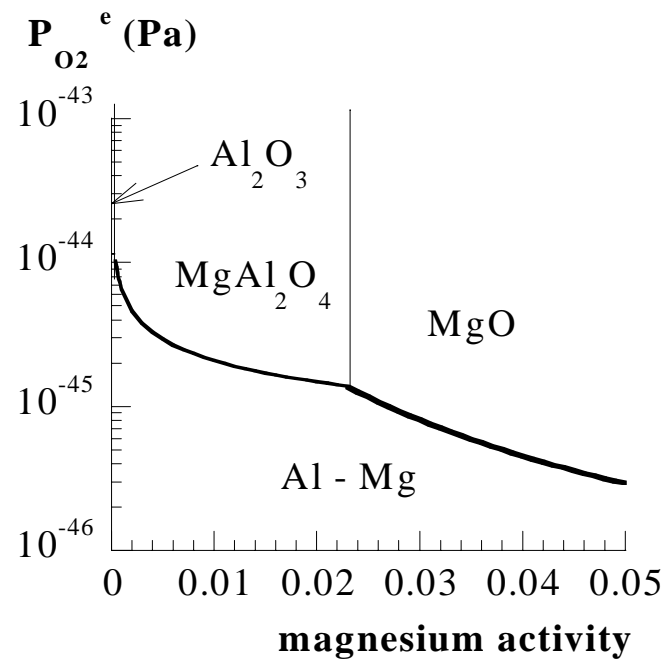

Figure 1: Thermodynamic stability of $\mathrm{MgO}, \mathrm{MgAl}_{2} \mathrm{O}_{4}$ and $\mathrm{Al}_{2} \mathrm{O}_{3}$ phases. Oxygen pressure at equilibrium versus magnesium activity.

During the oxidation experiments, a thin solid MgO layer is formed when the temperature increases, and when the alloy melts, it remains inside this solid layer which envelops the liquid metal. This layer undergoes strong deformations during the experiments, it is very rough and irregular. Its aspect varies from one experiment to another, as shown by the SEM micrographs of figure 2 , which represent the surface of two samples oxidised up to the same weight uptake $(0.7 \%)$, in the same conditions of temperature and pressure $\left(\mathrm{P}_{\mathrm{O} 2}=400 \mathrm{hPa}\right)$.
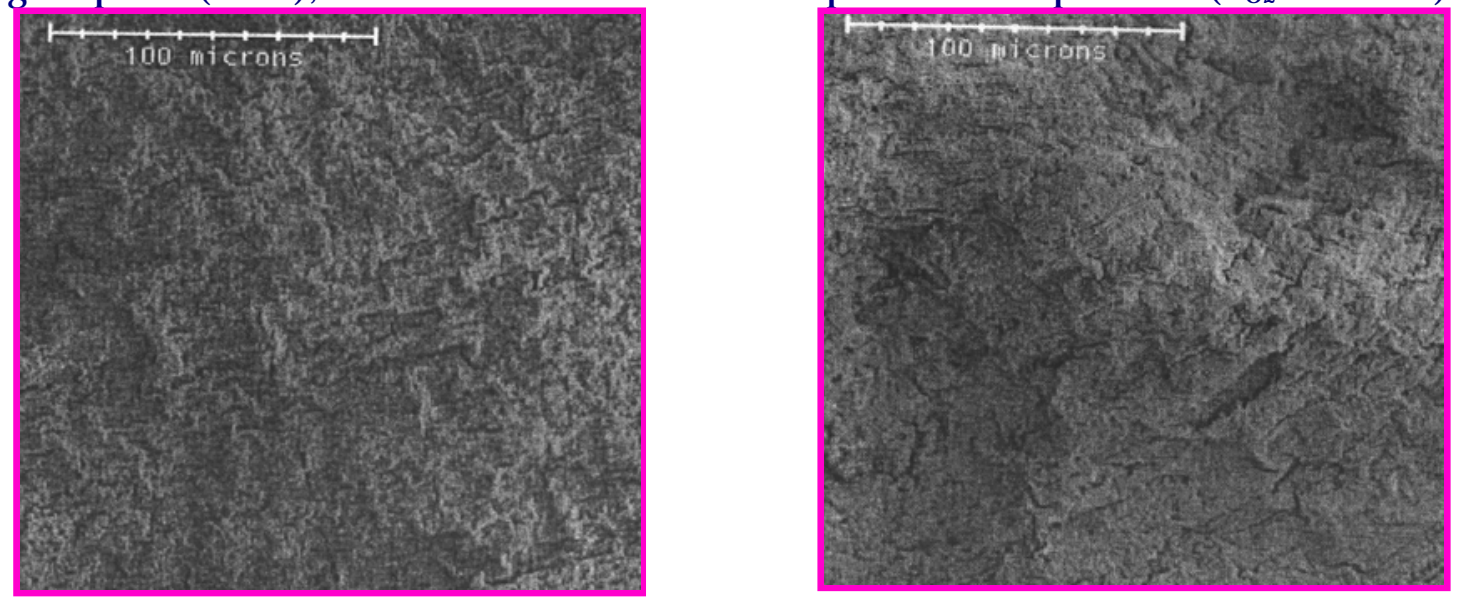

Figure 2: Surface morphology of two samples oxidised up to a weight uptake of $0.7 \%\left(\mathrm{~T}=700^{\circ} \mathrm{C}, \mathrm{P}_{\mathrm{O} 2}=\right.$ $400 \mathrm{hPa}$ ). 
SEM observations have also shown that the oxide layer is grey and formed of small MgO grains (about 0.5 $\mu \mathrm{m}$ ) (figure 3a) ; moreover, some holes are observed inside the samples, in which $\mathrm{MgO}$ cubes are located (5 to $10 \mu \mathrm{m})$ (figure $3 \mathrm{~b}$ ).

The shape of the curves obtained for oxygen pressures ranging from $200 \mathrm{hPa}$ to $800 \mathrm{hPa}$ is given in figure 4 : the curves are very irregular and not reproducible, which is not surprising since the samples undergo very important morphological changes during the reaction.
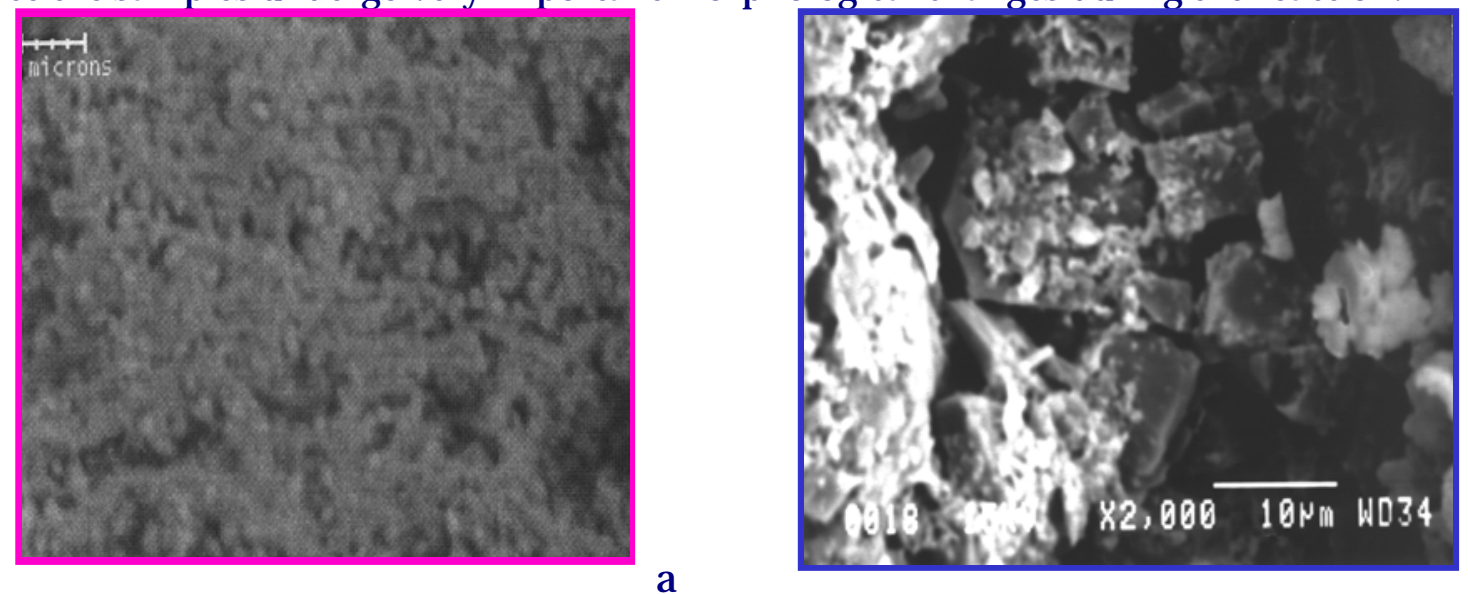

Figure 3: Morphology of the MgO oxide issued from the oxidation of Al-Mg5\% alloy: surface of the samples (a) and in the holes (b).

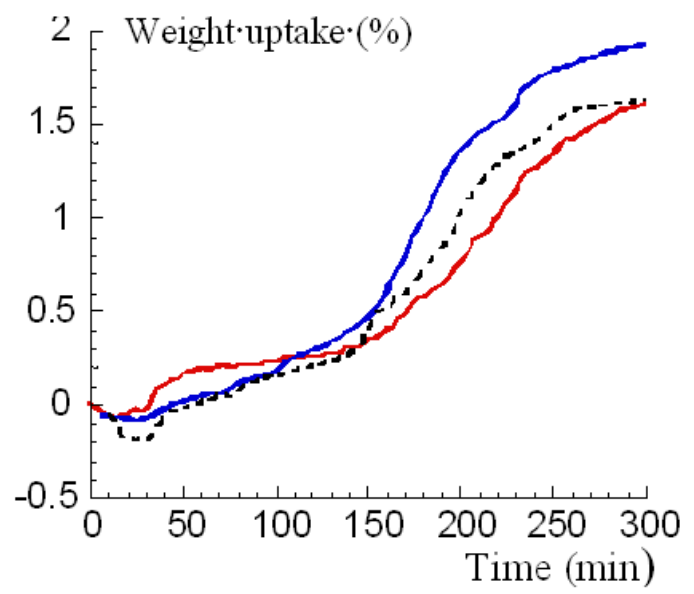

Figure 4: Curves of weight uptake and non reproducibility $\left(\mathrm{T}=700^{\circ} \mathrm{C}, \mathrm{P}_{\mathrm{O} 2}=400 \mathrm{hPa}\right)$

\section{KINETIC STUDY OF THE OXIDATION OF THE ALLOY}

\section{1: Method.}

The transformation of a solid involves the processes of nucleation and growth of the new phase (MgO in our case). The modelling of the transformation is simplified when the following assumptions are made (which can be verified experimentally):

(i) the system is in a quasi-steady state

(ii) the derivative of the fractional conversion $\alpha$ versus time, which be also called the rate, can be written:

$\mathrm{R}=\frac{\mathrm{d} \alpha}{\mathrm{dt}}=\Phi . \mathrm{E}$ 
where $\Phi$ is the areic « growth reactivity » of $\mathrm{MgO}$ (in mol.s $\mathrm{s}^{-1} \cdot \mathrm{m}^{-2}$ ), which depends on the physico-chemical variables (pressure $\mathrm{P}$, temperature $\mathrm{T}$, magnesium activity...), and $\mathrm{E}$ is the « space function » $\left(\mathrm{m}^{2} \cdot \mathrm{mol}^{-1}\right)$, characteristic of the extent of the reaction area where the ratelimiting step of the transformation occurs. E depends on the time and on the history of the solid from the beginning of the transformation up to the considered instant [2].

When these assumptions are verified, an experimental method, based on the isolation method [3], can be used to obtain directly the variations of $\Phi$ with the physico-chemical variables (particularly the oxygen pressure).

\section{2: Results.}

\section{2.a: Quasi-steady state}

It can be shown [4] that when a system is in a quasi-steady state, the curves giving the reaction rate versus time, obtained with two different experimental techniques, are affine, the axis being the rate axis and the direction the time axis.

We have chosen to measure simultaneously the oxidation rate by thermogravimetry and calorimetry (heat flow). The curves of rate of weight uptake and heat flow versus time have to be superimposed in two axis systems with different ordinate scales.

Figure 5 shows the curves obtained at $700^{\circ} \mathrm{C}$ for an oxygen pressure of $200 \mathrm{hPa}$.

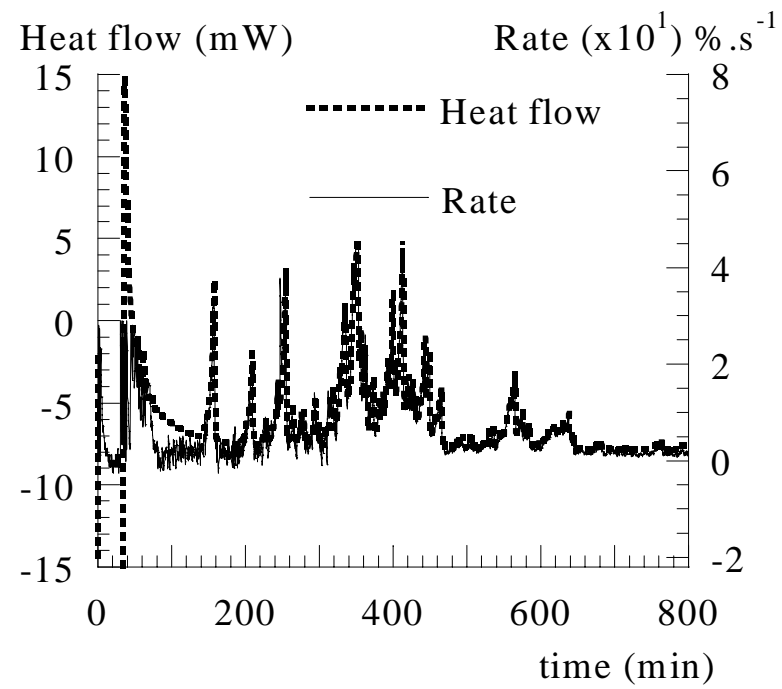

Figure 5: Quasi-steady state test $\left(700^{\circ} \mathrm{C}, \mathrm{P}_{\mathrm{O} 2}=200 \mathrm{hPa}\right)$

During the temperature increase $\left(10^{\circ} \mathrm{C} / \mathrm{min}\right)$, the alloy melting (at about $648^{\circ} \mathrm{C}$ ) induces a strong endothermic signal, which hides the exothermic signal due to the oxidation up to about 80 minutes (or $\Delta \mathrm{m}=0.4 \%$ ). Then, the curves are superimposed. Thus, the approximation of the quasi-steady state is valid at least from a weight uptake of $0.4 \%$, i.e. a fractional conversion equal to 0.12 .

\section{2.b: « $\Phi . E$. $»$ test.}

In order to verify that the rate $\mathrm{R}$ can be written as in Eq.[E.1], we use the isolation method, which consists into changing suddenly a physico-chemical variable $(P, T)$ from a value $Y_{0}$ to a value $Y_{1}$, at a given fractional conversion. Practically, we have changed the oxygen pressure from $200 \mathrm{hPa}$ to $400 \mathrm{hPa}$, at various fractional conversion, as indicated on figure 6 .

Let $\mathrm{R}_{\mathrm{bi}}\left(\mathrm{P}_{0}, \alpha_{\mathrm{i}}\right)$ and $\mathrm{R}_{\mathrm{ai}}\left(\mathrm{P}_{1}, \alpha_{\mathrm{i}}\right)$ be the rates before and after the pressure change at the fractional conversion $\alpha_{i}$, they can be written (cf. [E.1]) :

$\mathrm{R}_{\mathrm{bi}}\left(\mathrm{P}_{0}, \alpha_{\mathrm{i}}\right)=\Phi\left(\mathrm{P}_{0}\right) \mathrm{E}\left(\alpha_{\mathrm{i}}\right)$ and $\mathrm{R}_{\mathrm{ai}}\left(\mathrm{P}_{1}, \alpha_{\mathrm{i}}\right)=\Phi\left(\mathrm{P}_{1}\right) \mathrm{E}\left(\alpha_{\mathrm{i}}\right)$

so, their ratio is : 
$\frac{\mathrm{R}_{\mathrm{ai}}\left(\mathrm{P}_{1}, \alpha_{\mathrm{i}}\right)}{\mathrm{R}_{\mathrm{bi}}\left(\mathrm{P}_{0}, \alpha_{\mathrm{i}}\right)}=\frac{\Phi\left(\mathrm{P}_{1}\right) \mathrm{E}\left(\alpha_{\mathrm{i}}\right)}{\Phi\left(\mathrm{P}_{0}\right) \mathrm{E}\left(\alpha_{\mathrm{i}}\right)}=\frac{\Phi\left(\mathrm{P}_{1}\right)}{\Phi\left(\mathrm{P}_{0}\right)}$

The ratio of the rates before and after the pressure change does not depend on the fractional conversion : thus, the « $\Phi . E$ » test is verified if this ratio is constant, whatever the fractional conversion at which the pressure is changed is.

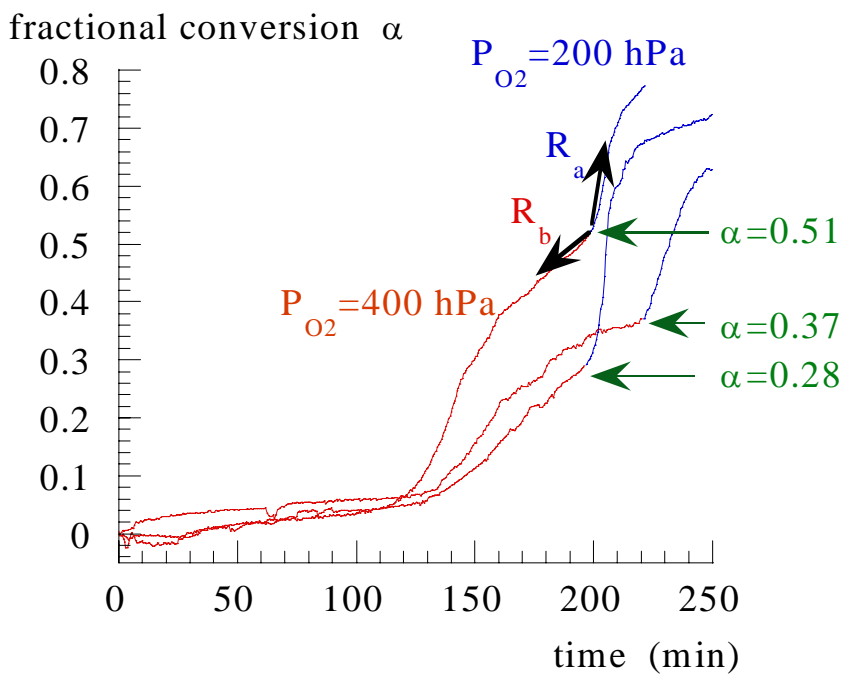

Figure 6: application of the isolation method to the « $\Phi$.E » test: oxygen pressure changes at various fractional conversions.

The test results are indicated in figure 7: two domains of weight uptake can be observed for which the « $\Phi . E$ » test is verified : the rates ratio is constant for a fractional conversion between 0.09 and 0.21 (weight uptake between $0.25 \%$ and $0.6 \%$ ), and then between 0.3 and 0.6 (weight uptake between 1 and $2 \%$ ), but the ratio value is different in each domain.

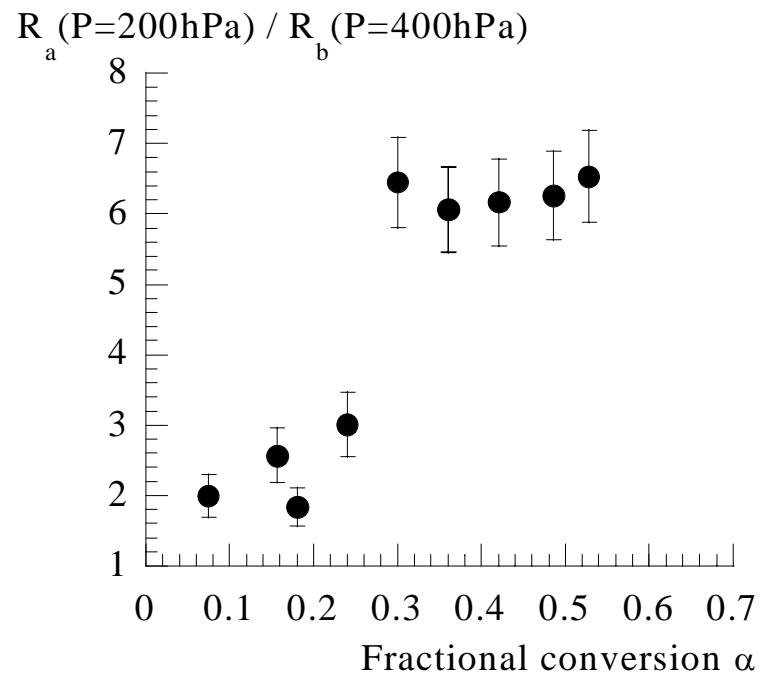

Figure 7: « $\Phi . \mathrm{E}$ » test by changing the oxygen pressure from $400 \mathrm{hPa}$ to $200 \mathrm{hPa}$.

Besides, it has been verified that when the pressure change is carried out at a given fractional conversion, the value of the rates ratio obtained in various experiments is nearly the same (error less than $10 \%$ ). Thus, the reactivity $\Phi$ is reproductible, the non reproducibility of the kinetic curves (figure 4) comes from the variations of the space function $\mathrm{E}$. 


\section{3: Variations of $\Phi$ with $\mathrm{P}_{\mathrm{O} 2}$ in each domain of weight uptake.}

The experimental method to obtain the variations of $\Phi$ with $\mathrm{P}_{\mathrm{O} 2}$ is also based on the isolation method: in that case, several changes are carried out at a given fractional conversion $\alpha_{i}$, from an oxygen pressure $\mathrm{P}_{0}$ (here $200 \mathrm{hPa}$ ) to various pressures $\mathrm{P}_{\mathrm{i}}$ (the temperature being constant).

The ratio of the rates before and after the change, equal to $\frac{\Phi\left(\mathrm{P}_{\mathrm{i}}\right)}{\Phi\left(\mathrm{P}_{0}\right)}$ from [E.2], is proportional to the variations of $\Phi$ with $\mathrm{P}_{\mathrm{O} 2},\left(\Phi\left(\mathrm{P}_{0}\right)\right.$ being a constant).

The variations of $\Phi$ with $\mathrm{P}_{\mathrm{O} 2}$ were obtained by changing the oxygen pressure at a fractional conversion 0.21 in the first domain of weight uptake $(\Delta \mathrm{m}<0.7 \%)$ and at 0.39 in the second domain of weight uptake $(1 \%<\Delta \mathrm{m}<2 \%)$. The figure 8 shows that in each domain, the growth reactivity decreases when the oxygen pressure increases, which is quite unusual for oxidation reactions.
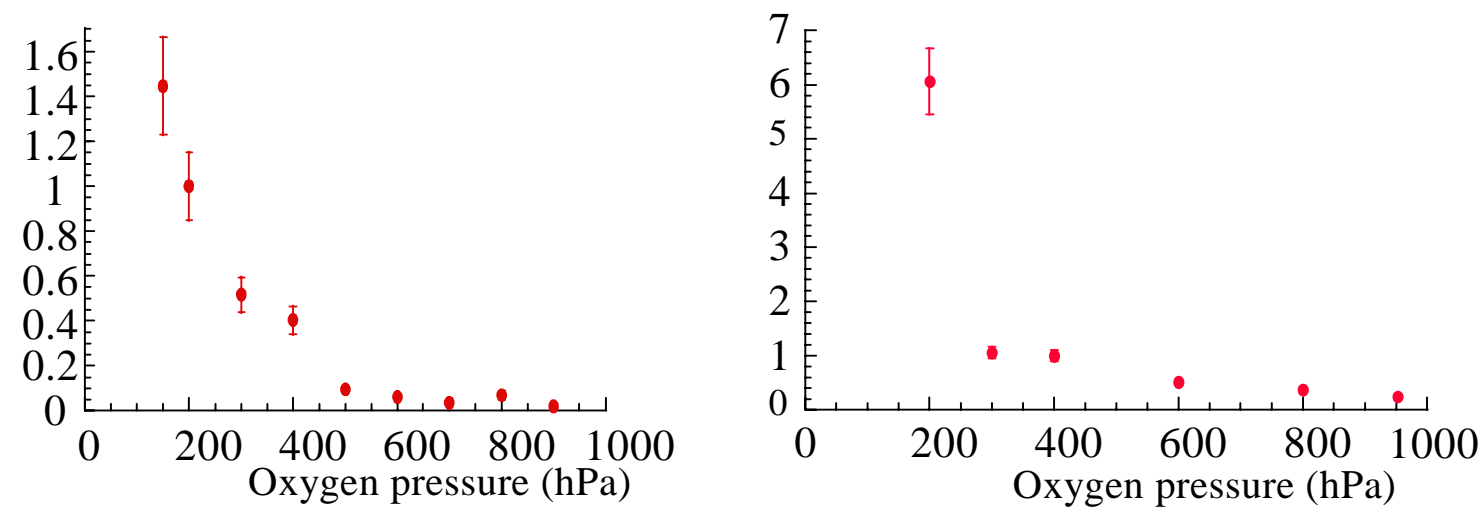

Figure 8: Variations of the growth reactivity $\Phi$ with oxygen pressure in each domain of weight uptake.

\section{Discussion and conclusions}

We have verified that we could assume that the system is in a quasi-steady state, and that the oxidation rate could be written as a product « $\Phi$.E ». These results are important for a further modelling of the reaction (with a reaction mechanism in elementary steps), because they mean that it will be possible to use the assumption of the rate-limiting step to calculate the rate laws issued from the reaction mechanism. Comparing these laws to the experimental variations of $\Phi$ with $\mathrm{P}_{\mathrm{O} 2}$ (Figure 8) will normally lead us to determine the rate-limiting step of the reaction and thus the appropriate rate law for $\Phi$. However, a qualitative description of the reaction mechanism can be attempted.

Usually, the mechanisms proposed to describe the oxidation of metals lead to an areic growth reactivity $\Phi$ which increases when the oxygen pressure increases [1].

In our case, to account for the inhibiting effect of oxygen on the growth reactivity of $\mathrm{MgO}$, we can consider a reaction mechanism involving two kinds of parallel oxygen adsorptions on the $\mathrm{MgO}$ surface, since several oxygen adsorbed species have already been observed on MgO [5]. Moreover we have carried out in-situ IR experiments during the oxidation of solid magnesium, showing that the $\mathrm{MgO}$ formation is accompanied by the appearance of a band at $1016 \mathrm{~cm}^{-1}$, characteristic of $\mathrm{O}_{2}^{-}$species, according to [6]. The IR spectra are given in figure 9 . 


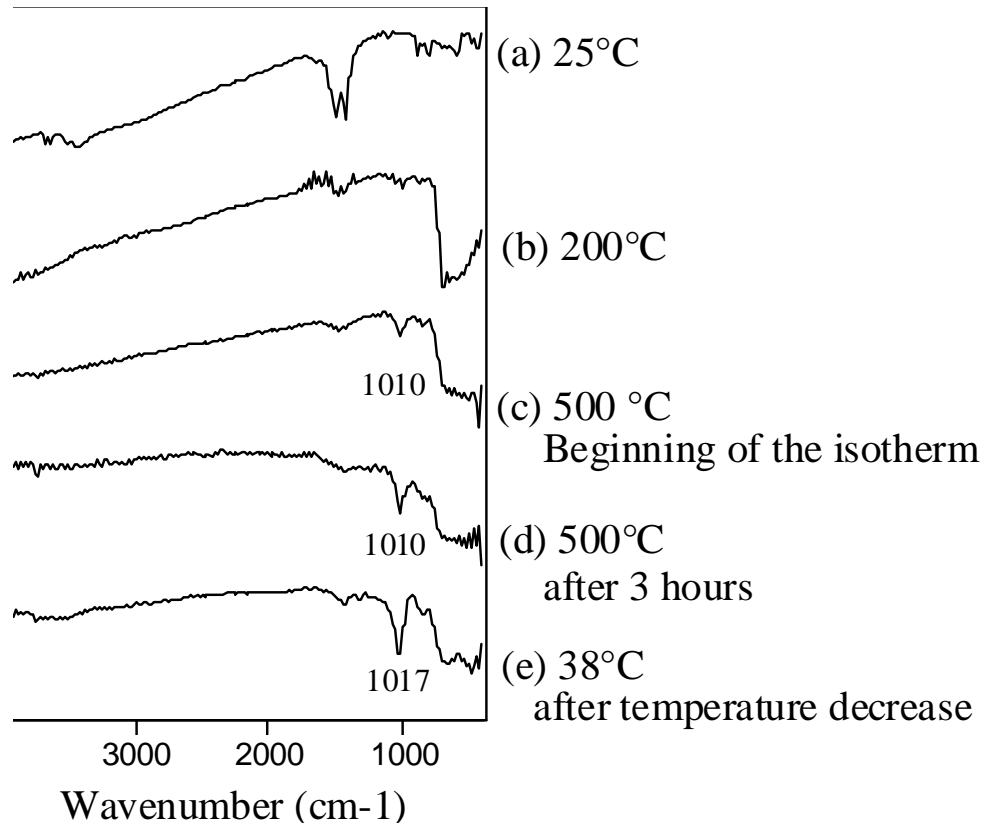

Figure 9: In-situ IR spectra during recorded during the oxidation of solid magnesium at $500^{\circ} \mathrm{C}$ by oxygen.

These $\mathrm{O}_{2}{ }^{-}$species are very stable, since the band at $1016 \mathrm{~cm}^{-1}$ is not modified at $500^{\circ} \mathrm{C}$ even when oxygen is suppressed from the gaseous atmosphere. They are supposed to be inactive for the oxidation, and to occupy adsorption sites. When the oxygen pressure increases, their concentration at the MgO surface increases as well, which could explain the experimental variations of $\Phi$ with the oxygen pressure.

Moreover, the proposal of a mechanism may lead to an interpretation for the existence of the two domains of weight uptake, in which $\Phi$ is not the same. These domains could be due for example, to a change in the $\mathrm{MgO}$ growth mechanism or to a change in the rate-limiting step of the same mechanism. Another explanation could be the predominant formation of the small grains in one part and of the larger cubes in the other part.

\section{References}

[1] K. Surla, F. Valdivieso, M. Pijolat, M. Prin, Etude de la cinétique d'oxydation des alliages aluminium-magnésium sous oxygène, Récents Progrès en Génie des Procédés, 55 (11), 87, (1997).

[2] M. Soustelle and M. Pijolat, Experimental methods useful in the kinetic modelling of heterogeneous reactions, Solid State Ionics, 95, 33, (1997).

[3] B. Delmon, in Introduction à la Cinétique Hétérogène, Ed. Technip, Paris, (1969).

[4] K. Surla, Oxydation d'un alliage aluminium-magnésium à l'état liquide. Méthodologie de détermination de mécanismes réactionnels à partir d'expériences non nécessairement reproductibles, Thesis, Saint-Etienne, (1998).

[5] C. Naccache, H. Che, Catalysis, Highwater editor, Vol.2, 1389, (1973).

[6] J.C. Lavalley, personal communication. 